\title{
Mechanism of Emission Reduction in HSDI Diesel Engine: Split Injection
}

\author{
K. Bala Showry ${ }^{a}$, P. Ravinder Reddy ${ }^{b} *$ A.V. Sita Rama Raju \\ ${ }^{a}$ DRK Institute of Science and Technology, Hyderabad, India, 500090 \\ ${ }^{b}$ Mechanical Engineering Department, CBIT Hyderabad, India, 500075 \\ ${ }^{c}$ Mechanical Engineering Department, JNTUH Hyderabad, India, 500085
}

\begin{abstract}
In order to meet the stringent emission standards significant efforts have been imparted to the research and development of cleaner IC engines. Diesel combustion and the formation of pollutants are directly influenced by spatial and temporal distribution of the fuel injected. The development and validation of computational fluid dynamics (CFD) models for diesel engine combustion and emissions is described. The complexity of diesel combustion requires simulation with many complex interacting sub models in order to have a success in improving the performance and to reduce the emissions. In the present work an attempt has been made to develop a multidimensional axe-symmetric model for CI engine combustion and emissions. Later simulations have been carried out using split injection for single, double and three pulses (split injection) for which commercial validation tool FLUENT was used for simulation. The tool solves basic governing equations of fluid flow that is continuity, momentum, species transport and energy equation. Using finite volume method turbulence was modeled by using RNG K- $\varepsilon$ model. Injection was modeled using La Grangian approach and reaction was modeled using non premixed combustion which considers the effects of turbulence and detailed chemical mechanism into account to model the reaction rates. The specific heats were approximated using piecewise polynomials. Subsequently the simulated results have been validated with the existing experimental values. The peak pressure obtained by simulation for single and double is $10 \%$ higher than to that of experimental value. Whereas for triple injections 5\% higher than to that of experimental value. For quadruple injection the pressure has been decreased by $10 \%$ when compared to triple injection. $\mathrm{NO}_{\mathrm{X}}$ have been decreased in simulation for single, double and triple injections by $15 \%, 28 \%$ and $20 \%$.For quadruple injection $\mathrm{NO}_{\mathrm{X}}$ were reduced in quadruple injection by $20 \%$ to that of triple injection. The simulated value of soot for single, double and triple injections are $12 \%, 22 \%$ and $12 \%$ lesser than the experimental values. For quadruple injection the soot levels were almost negligible. The simulated heat release rates for single, double and triple were reduced by $12 \%, 18 \%$ and $11 \%$. For quadruple injection heat release is reduced same as to that of triple injection.
\end{abstract}

Keywords: Split injection, Computational Fluid Dynamics, Start of injection, Duration of injection.

\section{Introduction}

Increasing environmental concerns and legislated emission standards have led to the necessity of considering both conventional and unconventional means for reducing soot and $\mathrm{NO}_{\mathrm{X}}$ emissions in diesel engines, which is also a motivation of the present study. For example, diesel engine

${ }^{*}$ Corresponding author. Tel.: +919700308734

Fax: +9876543210; E-mail: gurikini@ mail.com

(C) 2015 International Association for Sharing Knowledge and Sustainability

DOI: $10.5383 /$ ijtee.09.02.009 manufacturers are facing the challenges of the extremely low diesel engine -out soot emission mandates to be implemented in the near future. Engine simulation, compared to expensive engine experiments, is an efficient way to investigate various novel ideas to improve current engine performance, and hence becomes an essential part of engine research and development. In addition, simulations can investigate the transient properties of physical processes capabilities and model parameter uncertainties in many of the diesel spray and 
combustion related mechanisms limit the possibility of using detailed chemistry description of the soot formation process. On the other hand, the widely -applied and highly - efficient empirical soot models have become less sufficient for the emerging demands for accuracy and detailed soot particulate information. For example, newly proposed emission mandates will specifically enforce the emitted soot particulate's size. However, adequate accuracy of modeling particulate matter emission remains a challenge. Soot formation in diesel combustion involves both gas phase and particulate reaction mechanisms, therefore, it is more compared than other pollutant species such as $\mathrm{NO}_{\mathrm{X}}$ and $\mathrm{CO}$. Current computing power.

\section{Literature Review}

Multiple injections divide the total quantity of the fuel into two or more injections per combustion cycle. Splitting the injection sequence into two events is called pilot or split injection. A pilot injection is usually defined as an injection where $15 \%$ or less of the total mass of fuel is injected which reduces combustion noise and allow the use of poor ignition quality fuel (low cetane numbers) [2]. Many researchers are now investigating pilot and split injection as an effective means to simultaneously reduce $\mathrm{NO}_{\mathrm{X}}$ and particulate emission. Shundhoh.et al. [3] reported that $\mathrm{NO}_{\mathrm{X}}$ could be reduced by $35 \%$, and smoke by 60 to $80 \%$, without a penalty in fuel economy if pilot injection was used in conjunction with high pressure injection. Yamaki.et al. [4] investigated the effects of pilot injection on exhaust emissions in a turbocharged heavy duty Diesel engine and found that with partial load, when the pilot fuel quantity was increased, Fuel consumption and smoke was increased, but $\mathrm{NO}_{\mathrm{X}}$ was found to decrease and then increase. Minami et al. [5] studied the effects of pilot injection $\mathrm{s}$ in a turbocharged DI diesel engine and found that the pilot injection was effective to reduce $\mathrm{NO}_{\mathrm{X}}$ and $\mathrm{HC}$ at low load conditions, through it deteriorated smoke to some degree. Zhang et al. [6] used a single cylinder HSDI diesel engine to investigate the effect of pilot injection with EGR on soot, $\mathrm{NO}_{\mathrm{X}}$ and combustion noise, and found that the pilot injection increased soot emission. Nehmer and Reitz.et al. [7] Studied the effect of split injection in a heavy -duty diesel engine by varying the amount of fuel in first injection from 10 to $75 \%$ of the total amount of fuel. They found that split injection better utilized the air charge and allowed combustion to continue later into the power stroke than for a single injection case, without increased levels of soot production. Tow et al. [8] found that using a double injection with a relatively long dwell on a heavy duty engine resulted in reduction of particulate emissions by a factor of three with no increase in $\mathrm{NO}_{\mathrm{X}}$ and only a slight increase in BSFC compared to a single injection. Han et al. [9] Multidimensional computations carried out to understand the mechanism of soot and $\mathrm{NO}_{\mathrm{X}}$ emissions reduction in a heavy - duty diesel engine with multiple injections. The high momentum injected fuel penetrates to the fuel rich, relatively low temperature region at the jet tip and continuously replenishes the rich region, producing soot.However in a split injection, the second injection enters into a relatively fuel -lean and high temperature region that is left over from the combustion of first injection. Therefore, soot formation is significantly reduced. Tow et al. [8] pointed out that the dwell between injections was very important to control soot production and there would exist an optimal dwell at a particular engine operating condition. Durnholz.et al. [10] investigated the influence of pilot injection for a turbocharged and intercooled DI diesel engine for passenger cars. Their optimized pilot injection contained about $1.5 \mathrm{~mm}^{3}$ of the fuel in the pilot injection independent of engine load and their optimal dwell was $15^{\circ} \mathrm{CA}$. Fuchs and Rutland [1] found that high swirl ratios distributed the fuel such that it remained in the bowl, thus depleting almost all of the bowl oxygen during combustion. Therefore, they asserted that in high swirl ratio split injection cases the dwell should be optimized to prevent the second injection from landing in the fuel rich region left in the bowl from the first injection. D.A.Peirpont.et al. [11] Studied multiple injections are effective at reducing particulate. Two nozzle spray angles were used with included spray angles of $125^{\circ}$ and $140^{\circ}$ the results show that the combined use of EGR and multiple injections is very effective at simultaneously reducing particulate and $\mathrm{NO}_{\mathrm{X}}$. D.T.Montgomery et al.[12] observed the emissions and performance effects of exhaust gas recirculation (EGR) and multiple injections on the emission of oxides of nitrogen $\left(\mathrm{NO}_{\mathrm{X}}\right)$, particulate emissions, and brake specific fuel consumption (BSFC) over a wide range of engine operating conditions. $\mathrm{NO}_{\mathrm{X}}$ and particulate could be simultaneously reduced to 2.2 and 0.07 grams per bhp hour respectively. ManshikKim.et.al. [13] performed numerical simulations to investigate the combustion process in the Premixed Compression Ignition (PCI) regime in a lightduty diesel engine. Simulation results have shown good levels of agreement with the measured in-cylinder pressure, heat release rate and exhaust emissions. Mark P. et al. [14] worked on In-cylinder spray, mixing, combustion, and pollutant formation processes with early fuel injection (SOI=-22 $2^{\circ}$ ATDC) at two different charge densities were studied. Hardy et al. [15] performed Optimizations on a single-cylinder heavyduty. A micro-genetic algorithm was utilized to optimize a hybrid, double-injection strategy. The optimization produced a parameter set that met the 2007 and 2010 PM emissions mandate of $0.0134 \mathrm{~g} / \mathrm{kW}$ $\mathrm{hr}$, and was within the limits.

\section{Objectives}

The main objective of the present work is to improve the performance and simultaneous reduction of $\mathrm{NO}_{\mathrm{X}}$ and soot levels in the exhaust of high speed direct injection (HSDI) CI engine through simulation and experimentation by using split injection. 
- Performance improvement of high speed direct injection (HSDI) CI engine

- Simultaneous reduction in $\mathrm{NO}_{\mathrm{X}}$ and soot levels in the exhaust

\section{Methodology}

In order to achieve the above objectives the following methodology has been adopted.

- Geometric model is created in GAMBIT (preprocessor)

- Mesh creation

- Exporting the model from GAMBIT to FLUENT

- Defining the models to be used for the simulation

- Applying boundary conditions

- Applying material properties

- Activate the species transport and include the diesel species with PDF

- Activate second order upwind scheme for iterations

- Perform the iterations to converge

- $\quad$ Post processing the results

\section{Computational Fluid Dynamics}

CFD is a sophisticated analysis technique that the analyst to predict transfer of heat, chemical reaction, and fluid flow behavior etc. CFD is based on the fundamental governing equations of fluid dynamics- the continuity, momentum, and energy equation. It is a powerful tool to carry out numerical experiments. This research uses the Computational Fluid Dynamics FLUENT 6.3 software package. The process of utilizing FLUENT can be assumed in firstly, the geometry and gird is created using GAMBIT. T Grid can be used to generate $2 \mathrm{D}$ triangular, $3 \mathrm{D}$ tetrahedral or $2 \mathrm{D}$ and $3 \mathrm{D}$ hybrid volumes mesh from an existing boundary mesh. Another alternative of creating grids for FLUENT is using ANSYS or IDEAS and Geo Mesh are the names of FLUENT Pre-processors that were used before the introduction of GAMBIT. Once a grid has been read into FLUENT, all remaining operations are performed with in the solver. These include setting the boundary conditions, defining fluid properties, and material properties, executing the solution, refining the grid, viewing and post- processing the results.

\subsection{Governing Equation}

In CFD, fluid flows are stimulated by numerical solving partial differential equations that governs the transport of flow quantities also known as flow variables. These variables include mass, momentum, energy, turbulent quantities, and species concentrations. In designing the POME- nozzle, the basic governing equations that will be used are the conservation of mass, momentum and energy equations.

\subsection{Discretization Method}

The method contains settings that control the discretization of the convection terms in the solution equations. It is a numerical method to solve the above equation by discretization to the partial differential Equations on a computational grid, the formation of a set algebraic equations and the solution of the algebraic equations. FLUENT allows choosing the discretization scheme for the convection terms of each governing equation. The numerical method is a discrete solution of the flow field, which is comprised of the values of the flow variables at the grid points. One of the most important terms that need to be discretized is convection. Second- order accuracy is automatically used for the viscous terms. The mathematical code uses a control volume technique to covert the governing equations that can be solved numerically. It consists of integration the governing equations about each control volume.

\subsection{Upwind Scheme}

Due to the computational domain, the initialized values are quite different from those expected in the final solution after the iteration process has begun. For this reason, first order UPWIND scheme is utilized until a more realistic solution is achieved, after which a more accurate second order UPWIND scheme could be implemented.

\subsection{Application of CFD}

CFD is useful tool in performing theoretical experimental validation. It solves all problems concerning fluid flows such as incompressible and compressible flow. Newtonian or non Newtonian flow, swirl, transfer of heat, in viscid, laminar and turbulent flow, radiation ,mixing, chemical reaction, spray models etc. CFD can be applied to solve industrial flow problems due to rapid growth of powerful computer resources and the development of CFD software packages. In engineering applications, it is much cheaper to use CFD than conventional design process. In CFD simulation, we can simulate different set of parameters for the same design without any additional cost. This reduces the time and cost of experimental work.

\section{Mathematical Modeling and Simulation}

To predict the parameters cycle peak pressures, heat release rate, temperature and the influence of different parameters on the formation of oxides of nitrogen, carbon monoxide, and soot using CFD technique, the following flow governing equations are to be solved. 


\subsection{Continuity and Momentum Equation}

For all flows, FLUENT solves conservation equations for mass and momentum. For flows involving heat transfer or compressibility, an additional equation for energy conservation is solved. For flows involving species mixing or reactions, a species conservation equation is solved or if the non premixed combustion model is used, conservation equations for the mixture fraction and its variance are solved. Additional transport equations are also solved when the flow turbulent. The conservation equations relevant to heat transfer, turbulence modeling and species transport will be discussed here.

\subsubsection{The Mass Conservation Equation}

$\frac{\partial p}{\partial t}+\nabla \cdot(\rho \vec{v})=S_{m}$

Equation (1) is the general form of the mass conservation equation and is valid for incompressible flows. The source $S_{m}$ is the mass added to the continuous phase from the dispersed second phase and any user-defined sources.

For 2D Axi -symmetric geometries, the continuity equation is given by

$$
\frac{\partial p}{\partial t}+\frac{\partial}{\partial x}\left(\rho v_{x}\right)+\frac{\partial}{\partial r}\left(\rho v_{r}\right)+\frac{\rho v_{r}}{r}=S_{m}
$$

Where $x$ is the axial coordinate, $r$ is the radial coordinate, $v_{x}$ is the axial velocity, and $v_{r}$ is the radial velocity.

\subsubsection{Momentum Conservation Equations}

Conservation of momentum in an inertial (non accelerating) reference is given by

$$
\frac{\partial}{\partial t}(\rho \vec{v})+\nabla \cdot(\rho \vec{v} \vec{v})=-\nabla p+\wp \nabla \cdot(\overline{\bar{T}})+\rho \vec{g}+\vec{F}
$$

Where $p$ is static pressure, $\overline{\bar{T}}$ is the stress tensor (described below), and $\rho \vec{g}$ and $\vec{F}$ are the gravitational body force and external body forces respectively. $\vec{F}$ also contains other model -dependent source terms such as porous media and user defined sources.

The stress tensor $\overline{\bar{T}}$ is given by

$$
\bar{T}=\mu\left[\left(\nabla \vec{v}+\nabla \vec{v}^{T}\right)-\frac{2}{3} \nabla \cdot \vec{v} I\right]
$$

where $\mu$ is the molecular viscosity, $I$ is the unit tensor, and second term on the right hand side is the effect of volume dilation.

For 2D axi-symmetric geometries, the axial and radial momentum conservation equations are given by

$\frac{\partial}{\partial t}\left(\rho v_{x}\right)+\frac{1}{r} \frac{\partial}{\partial x}\left(r \rho v_{x} v_{x}\right)+\frac{1}{r} \frac{\partial}{\partial r}\left(r \rho v_{r} v_{x}\right)=-\frac{\partial p}{\partial x}+\frac{1}{r} \frac{\partial}{\partial x}\left[r \mu\left(2 \frac{\partial v_{x}}{\partial x}-\frac{2}{3}(\nabla \cdot \vec{v})\right)\right]+$

$\frac{1}{r} \frac{\partial}{\partial r}\left[r \mu\left(\frac{\partial v_{x}}{\partial r}+\frac{\partial v_{r}}{\partial x}\right)\right]+F_{x}$

And

$$
\begin{aligned}
& \frac{\partial}{\partial t}\left(\rho v_{r}\right)+\frac{1}{r} \frac{\partial}{\partial x}\left(r \rho v_{x} v_{r}\right)+\frac{1}{r}\left(r \rho v_{r} v_{r}\right) \\
& =-\frac{\partial p}{\partial r}+\frac{1}{r} \frac{\partial}{\partial x}\left[r \mu\left(\frac{\partial v_{r}}{\partial x}+\frac{\partial v_{x}}{\partial r}\right)\right] \\
& +\frac{1}{r} \frac{\partial}{\partial r}\left[r \mu\left(2 \frac{\partial v_{r}}{\partial r}-\frac{2}{3}(\nabla \cdot \vec{v})\right)\right] \\
& -2 \mu \frac{v_{r}}{\partial r}+\frac{2}{3} \frac{\mu}{r}(\nabla \cdot \vec{v})+\rho \frac{v_{z}^{2}}{r}+F_{r}
\end{aligned}
$$

Where

$\nabla \cdot \vec{v}=\frac{\partial v_{x}}{\partial x}+\frac{\partial v_{r}}{\partial r}+\frac{v_{r}}{r}$

and $v_{z}$ is the swirl velocity.

\section{Computational Mesh}

The computational mesh used in this analysis is presented in Fig. 1



Figure. 1 Computational Mesh 


\section{Engine Specifications used for Simulation}

Table 1 presents the simulation details of the engine used in this paper. Also, table 2 describes the fuel system specifications.

Table 1

Simulation Engine Details

\begin{tabular}{||l|l||}
\hline Engine Type & $\begin{array}{l}\text { Caterpillar 3406, Single } \\
\text { Cylinder Direct Injection, 4 } \\
\text { Valve }\end{array}$ \\
\hline Bore & $137.2 \mathrm{~mm}$ \\
\hline Stroke & $165.2 \mathrm{~mm}$ \\
\hline Compression ratio & $15.1: 1$ \\
\hline Engine speed & $2100 \mathrm{rpm}$ \\
\hline Atomization & Pressure swirl \\
\hline $\begin{array}{l}\text { Atomizer dispersion } \\
\text { angle }\end{array}$ & $6^{\circ}$ \\
\hline
\end{tabular}

Table 2

Fuel System Specifications

\begin{tabular}{||l|l||}
\hline Injector Type & $\begin{array}{l}\text { Electronically Controlled } \\
\text { Common Rail Injector }\end{array}$ \\
\hline Injection pressure & Variable up to 120 M pa \\
\hline Number of orifices & 6 \\
\hline orifice diameter & $0.26 \mathrm{~mm}$ \\
\hline Spray included angle & $140^{\circ}$ \\
\hline Injection Approach & La-grangian \\
\hline Turbulence model & RNG K- $\varepsilon$ \\
\hline Mass flow rate & $0.0356 \mathrm{~kg} / \mathrm{sec}$ \\
\hline Time step & $6.6666^{*} \mathrm{e}-5$ \\
\hline Start of injection & $20^{\circ} \mathrm{bTDC}$ \\
\hline Duration of injection & $24^{\circ}$ \\
\hline Fuel & Diesel \\
\hline \hline
\end{tabular}

\section{Validation of Simulation Results}

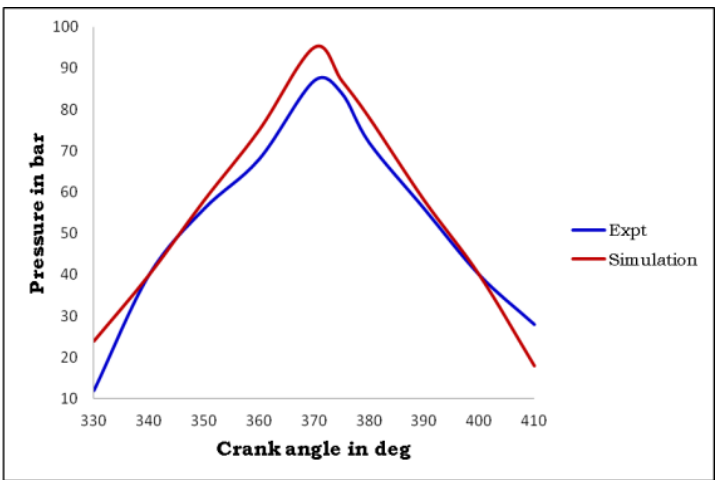

Figure 2 P- $\theta$ Curve for single injection

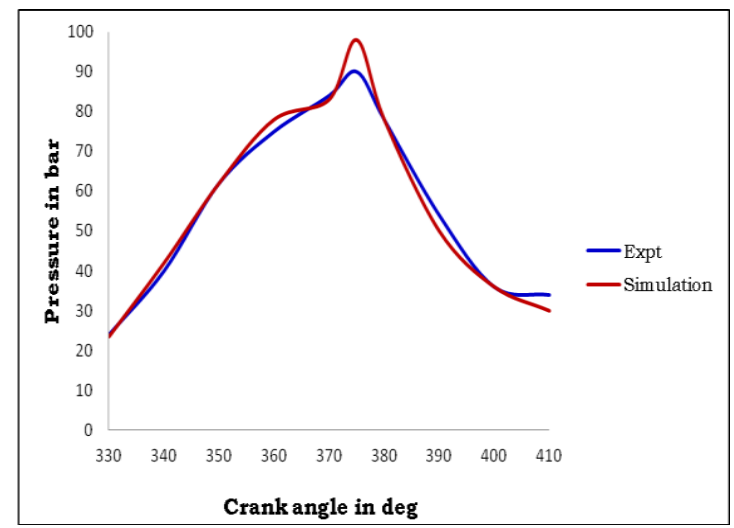

Figure 3 P- $\theta$ Curve for double injection

Figs 2 to 4 show comparison of P- $\theta$ curves obtained by simulation to the existing experimental results for single, double, and triple injections. For double injection the dwell considered was $10^{\circ}$, where as for triple injection it was $20^{\circ}$. For single and double injection peak cycle Pressure has been increased nearly by $8.4 \%$ and $8.16 \%$ for triple injection it was nearly $3.22 \%$. As number of pulses increases, peak pressure is closely following the experimental value.

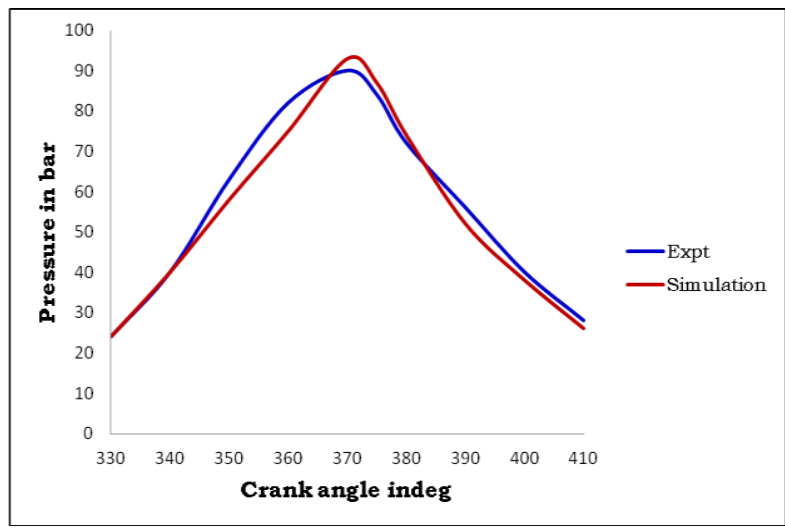

Figure 4 P- $\theta$ Curve for triple injection 


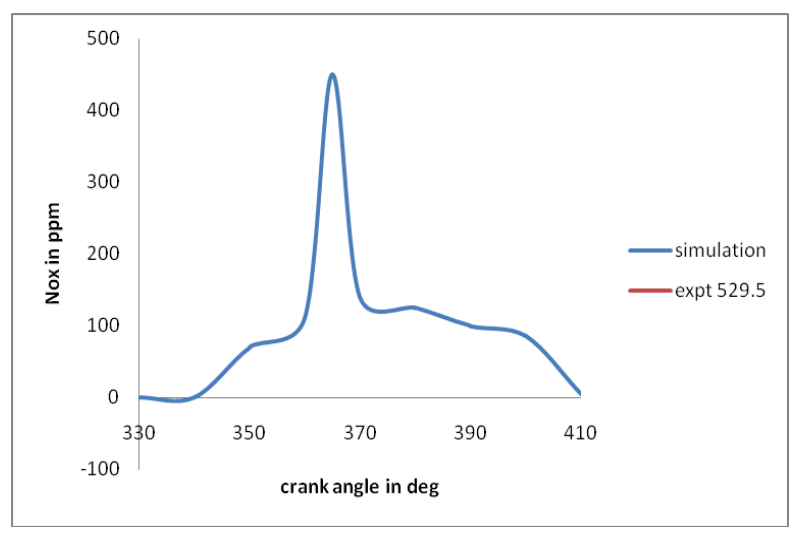

Figure $5 \mathrm{NO}_{\mathrm{X}}$ Curve for Single Injection

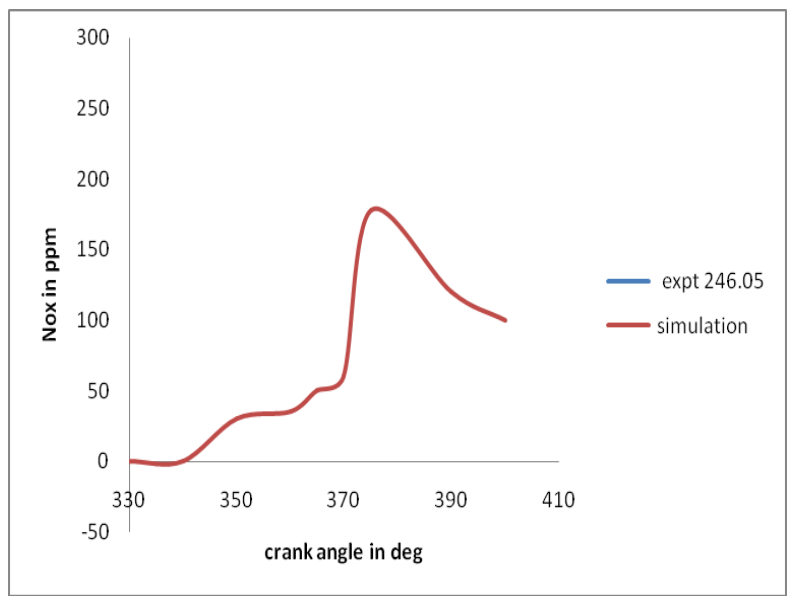

Figure $6 \mathrm{NO}_{\mathrm{X}}$ Curve for double Injection

Figs. 5 to 7 show the comparison of $\mathrm{NO}_{\mathrm{X}}$ curves are in obtained by simulation to the existing experimental results for single, double, and triple injections. For single and double injections $\mathrm{NO}_{\mathrm{X}}$ are reduced by nearly $15 \%$ and $28 \%$, where as for triple injection nearly $20 \%$ has been reduced.

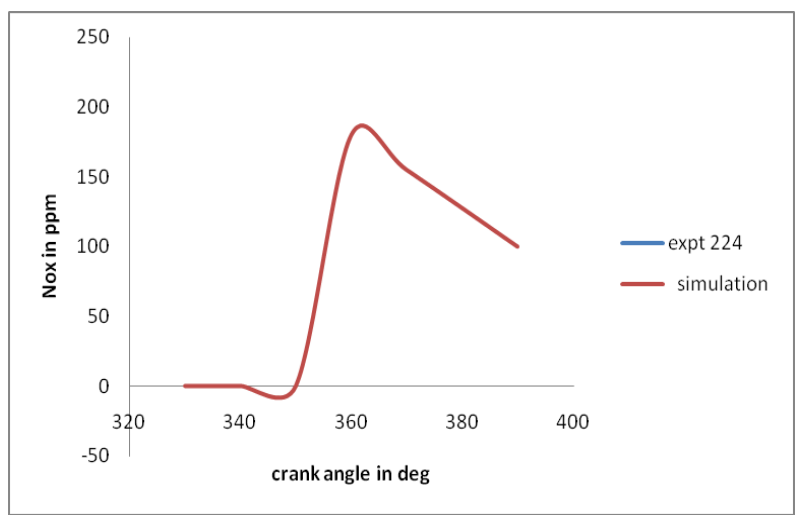

Figure $7 \mathrm{NO}_{\mathrm{X}}$ Curve for triple Injection

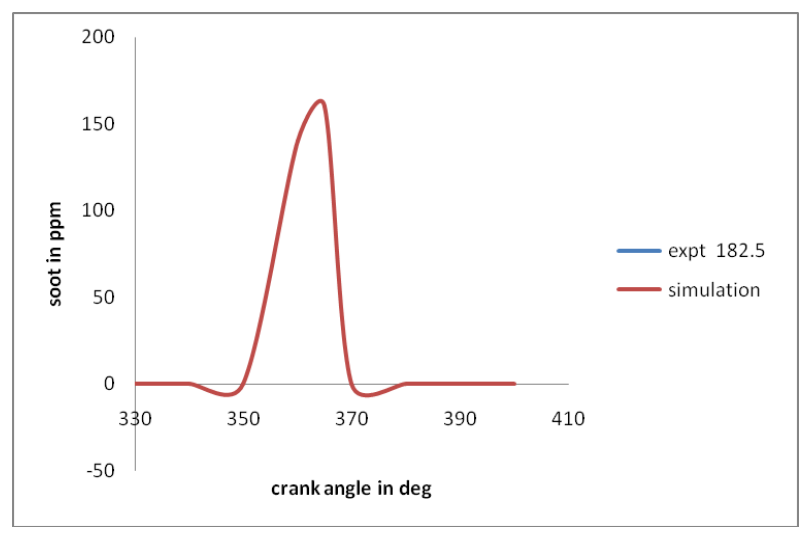

Figure 8 Soot Curve for single Injection

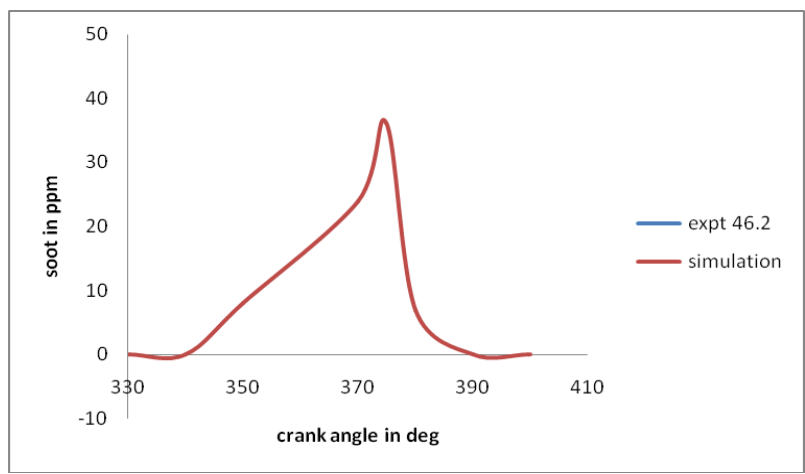

Figure 9 Soot Curve for double Injection

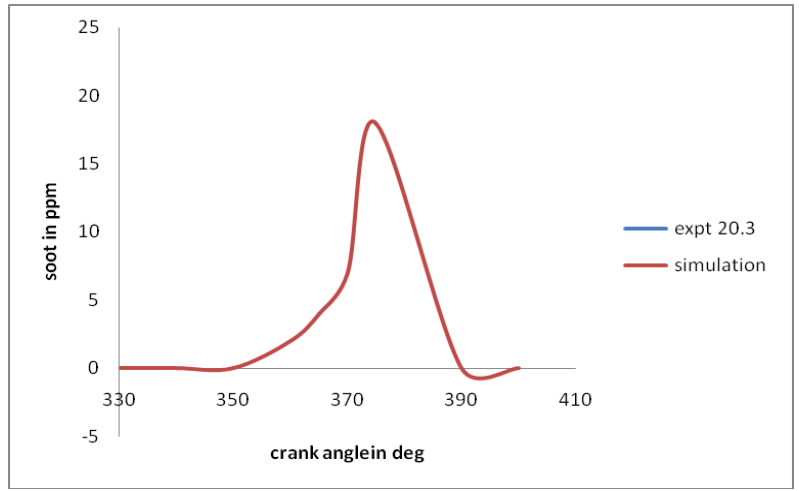

Figure 10 Soot Curve for triple Injection

Figs 8 to 10 show comparison of soot curves obtained by simulation to the existing experimental results for single, double, and triple injections. For single injection soot has been decreased $12.32 \%$, for double and triple injections there was a reduction by nearly $21.6 \%$ and $11.33 \%$ respectively. Regarding soot reduction, soot formation is reduced after the injection pause between injection pulses. The reduced soot formation was due to the fact that soot producing rich regions at the spray tip are no longer replenished. During the dwell between injection pulses, the mixture becomes leaner. With multiple injections, multiple soot formation regions are formed in the combustion chamber, but, since the subsequent injections take place into a high temperature environment left from the combustion products of the 
first injection, the injected fuel burns more rapidly, soot formation rates are decreased, and the net soot production can be reduced dramatically.

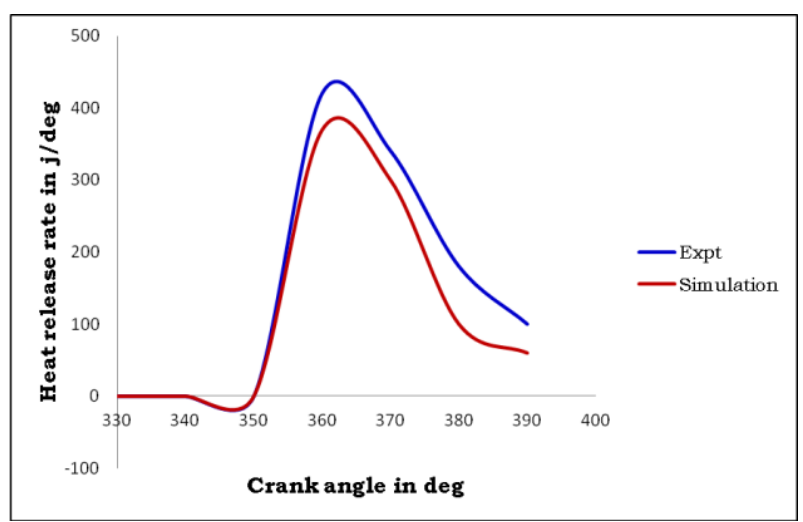

Figure 11 heat release rate curve for single Injection

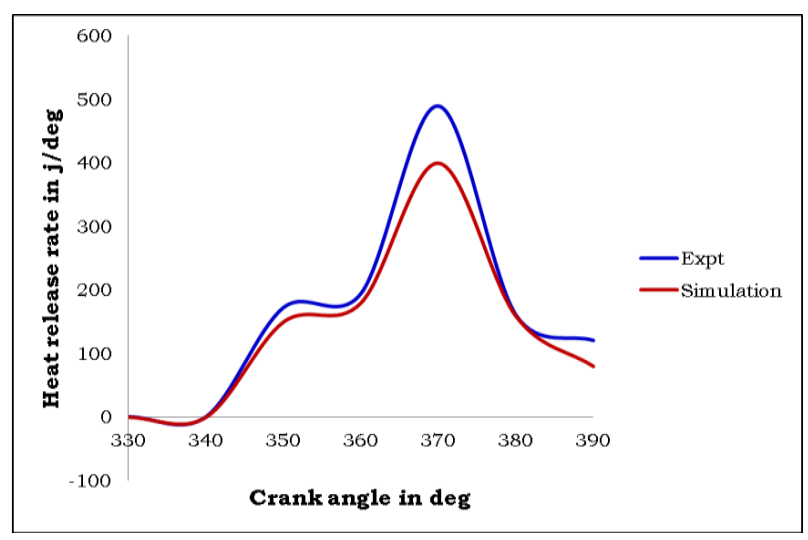

Figure 12 heat release rate curve for double Injection

Figs. 11 to 13 show comparison of heat release rate curves obtained by simulation to the existing experimental results for single, double, and triple injections. For single, double and triple injections heat release rates have been decreased nearly by $11.9 \% \mathrm{j} /$ ${ }^{\circ} \mathrm{CA}, 18.2 \% \mathrm{j} /{ }^{\circ} \mathrm{CA}, 11.76 \% \mathrm{j} /{ }^{\circ} \mathrm{CA}$.

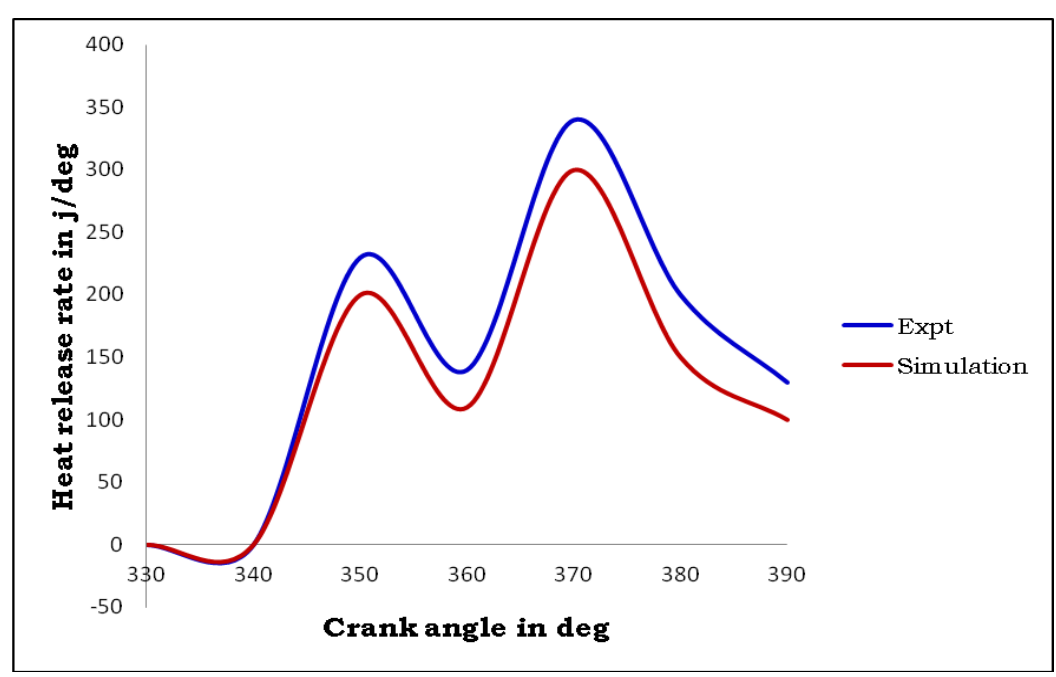

Figure 13 heat release rate curve for triple Injection

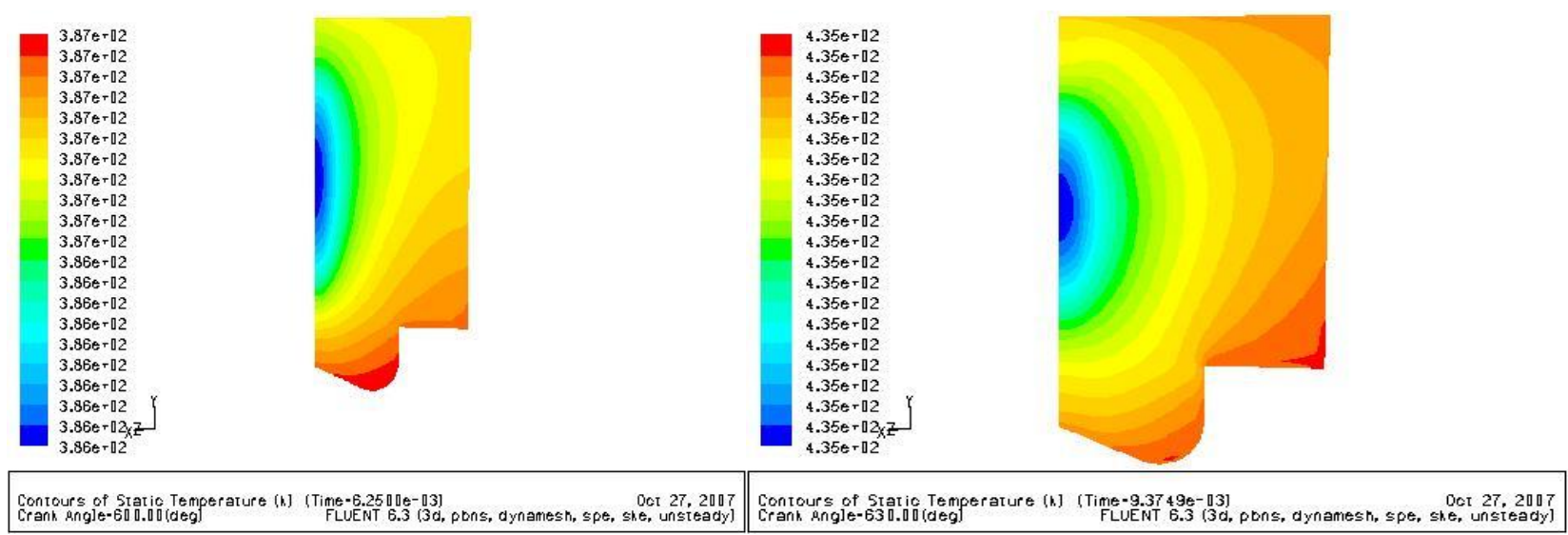

Figure 14 Contours of static temperature 


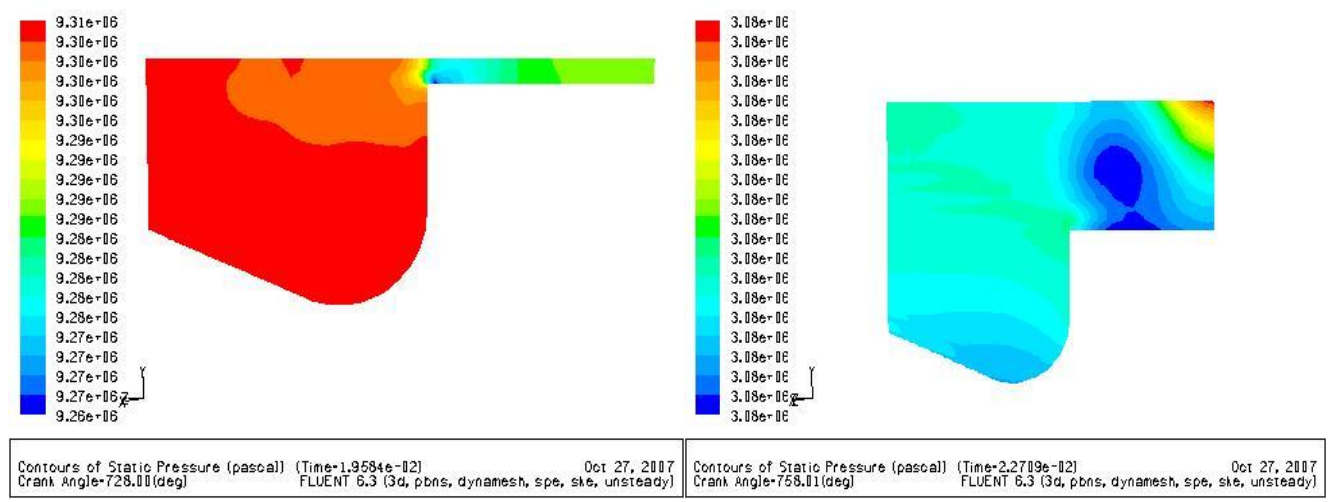

Figure 15 Contours of static pressure

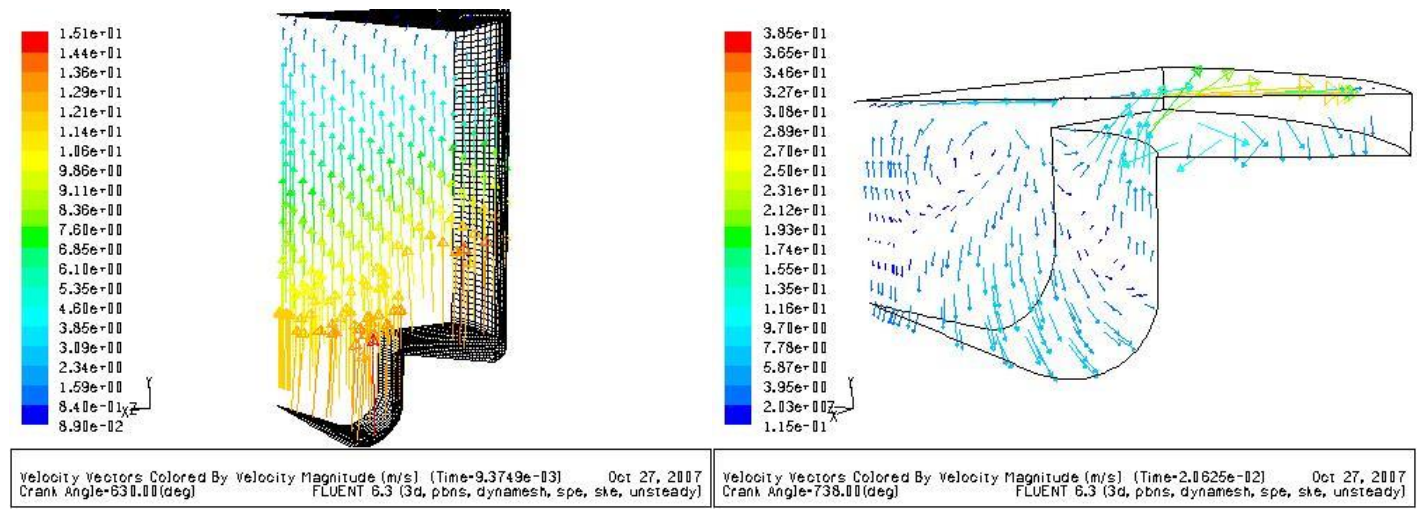

Figure 16 Contours of spray



Figure 17Contours of Turbulent kinetic energy 


\section{Conclusions}

- Peak cycle pressure observed for simulation and experiment are 95 bar and 87 bar respectively for single injection.

- In two pulse injection 98bar was observed as peak cycle pressure for simulation, whereas 90 bar was observed as cycle peak pressure from simulation.

- The maximum cycle pressure was observed for triple injection from experiment and CFD code is $90 \mathrm{bar}$ and $93 \mathrm{bar}$ respectively.

- During four pulse injection simulated cycle peak pressure was observed as 77.8bar.

- It was observed that for single injection the cycle peak pressure has been increased by $8.42 \%$ when compared to the existing experimental results. For two pulses peak cycle pressure is increased by $8.16 \%$ compared to experimental value, where as for triple injection the cycle peak pressure was increased by $3.22 \%$ compared to the existing experimental results. It was observed that as numbers of pulses are increasing the peak cycle pressure was closely following the experimental value. The reason for increment in peak cycle pressure for single double and triple injections is that almost all particles injected during are participating in combustion.

- $\quad$ During single injection with CFD code, $\mathrm{NO}_{\mathrm{X}}$ was observed as $450 \mathrm{pm}$ and experimental value was 529.5ppm.

- In two pulses injection with a dwell of $10^{\circ}$, $\mathrm{NO}_{\mathrm{X}}$ were observed as $177.8 \mathrm{ppm}$ and the measured value is $246.05 \mathrm{ppm}$.

- $\quad$ For double dwell of $20^{\circ} \mathrm{CA}, \mathrm{NO}_{\mathrm{X}}$ obtained from code was $186 \mathrm{ppm}$ and experimental value was $224 \mathrm{ppm}$.

- In quadruple injection $\mathrm{NO}_{\mathrm{X}}$ emissions were almost negligible.

- $\quad \mathrm{NO}_{\mathrm{X}}$ have been reduced during simulation for single, double, and triple injections by $15.01 \%$, $27.7 \%$ and $19.64 \%$ compared to the existing experimental results. It was observed that $\mathrm{NO}_{\mathrm{X}}$ emissions for single and triple injections with code are closely following measured values.

- In direct injection using CFD code Soot was observed as $160 \mathrm{ppm}$ and the measured value is $182.5 \mathrm{ppm}$.
- In single dwell of $10^{\circ} \mathrm{CA}$, soot was observed as $36.2 \mathrm{ppm}$ and the measured value is $42.6 \mathrm{ppm}$.

- In triple injection soot obtained by code was $18 \mathrm{ppm}$ and the measured value is $20.3 \mathrm{ppm}$.

- In quadruple injection soot emissions were almost negligible.

- For single injection soot has been decreased $12.32 \%$, for double and triple injections there was a reduction by nearly $21.6 \%$ and $11.33 \%$ respectively. For single injection and triple injection the soot emissions by code are closely following the experimental values.

- The Heat release rate measured for direct injection by simulation was $370 \mathrm{j} /{ }^{\circ} \mathrm{CA}$ and where as the experimental value was $420 \mathrm{j} /{ }^{\circ} \mathrm{CA}$.

- In two pulses injection Heat release rate by was observed by code as $400 \mathrm{j} /{ }^{\circ} \mathrm{CA}$ by and that of measured value is $489 \mathrm{j} /{ }^{\circ} \mathrm{CA}$.

- For two dwell injection, Heat release rate from simulation was $300 \mathrm{j} /{ }^{\circ} \mathrm{CA}$, and where as the experimental value is $340 \mathrm{j} /{ }^{\circ} \mathrm{CA}$.

- The heat release rate simulated during the operating cycle is $325 \mathrm{j} /{ }^{\circ} \mathrm{CA}$ for quadruple injection.

- Heat release rates have been decreased by $11.9 \% \mathrm{j} /{ }^{\circ} \mathrm{CA}, 18.2 \% \mathrm{j} /{ }^{\circ} \mathrm{CA}$ and $11.76 \% \mathrm{j} /{ }^{\circ} \mathrm{CA}$ when compared to measured values. But for direct injection and triple injection the heat release rates are closely following the experimental values.

\section{References}

[1] Fuchs, T.R. and Rutland, C.J., "Intake Flow Effects on Combustion and Emissions in a Diesel Engine", SAE Paper 980508, 1998.

[2] Jafer, D., "Pilot Injection", Engineering. October 15, 1937.

[3] Shundoh, S., Komori, M., Tsujimura, K., and Kobayashi, S., " $\mathrm{NO}_{\mathrm{X}}$ Reduction from Diesel Combustion Using Pilot Injection with High-Pressure Fuel Injection”, SAE Paper 920461, 1992:25-36

[4] Yamaki, Y. et.al. "Application of Common Rail Fuel Injection System to a Heavy Duty Diesel Engine", SAE Paper 94229, 1994:85-96

[5] Miyami, T., Takeuchi, K., and Shimazaki, N., "Reduction of Diesel Engine $\mathrm{NO}_{\mathrm{X}}$ Using Pilot Injection”. SAE Paper 950611, 1995:89-96

[6] Zhang, Long, "A Study of Pilot Injection in a DI Diesel Engine”, SAE Paper 1999-01-3493, 1999:1-8 
[7] Nehmer, D.A. and Reitz, R.D., "Measurement of the Effect of Injection Rate and Split Injections on Diesel Engine Soot and $\mathrm{NO}_{\mathrm{X}}$ Emissions", SAE Paper940668, 1994:55-66

[8] Tow, T.C., Pierpont, A., and Reitz, R.D., "Reducing Particulates and $\mathrm{NO}_{\mathrm{X}}$ Emissions by Using Multiple Injections in a Heavy Duty D.I. Diesel Engine", SAE Paper 940897, 1994:1-14

[9] Han, Z., Ulugogan, A., Hampson, G.J., and R.D.Reitz, "Mechanism of Soot and $\mathrm{NO}_{\mathrm{X}}$ Emission Reduction Using Multiple -Injection in a Diesel Engine", SAE Paper 960633, 1996:87-102

[10] Durnholz, M., Endres, H., and Frisse, P., "Pre injection A Measure to Optimize the Emission Behavior of DKDiesel Engine “, SAE Paper 940674, 1994:123-129

[11] D.A. Pierpont, D.T. Montgomery, and Reitz, "Reducing Particulate and $\mathrm{NO}_{\mathrm{X}}$ Using Multiple
Injections and EGR in a D.I. Diesel" SAE 950217 1995:1-13

[12] D. T. Montgomery and R. D. Reitz "Six-Mode Cycle Evaluation of the Effect of EGR and Multiple Injections on Particulate and $\mathrm{NO}_{\mathrm{X}}$ Emissions from a D.I. Diesel Engine" SAE 960316 1996:113-130

[13] Manshik Kim and Rolf D. Reitz "Modeling Early Injection Processes in HSDI Diesel Engines" SAE 2006-01-0056 2006:3-14

[14] Mark P. B. Musculus "Multiple Simultaneous Optical Diagnostic Imaging of Early-Injection LowTemperature Combustion in a Heavy-Duty Diesel Engine" SAE 2006-01-0079 2006:1-30

[15] W. L. Hardy and R. D. Reitz "An Experimental Investigation of Partially Premixed Combustion Strategies Using Multiple Injections in a Heavy-Duty Diesel Engine" SAE 2006-01-0917 2006:1-20 